
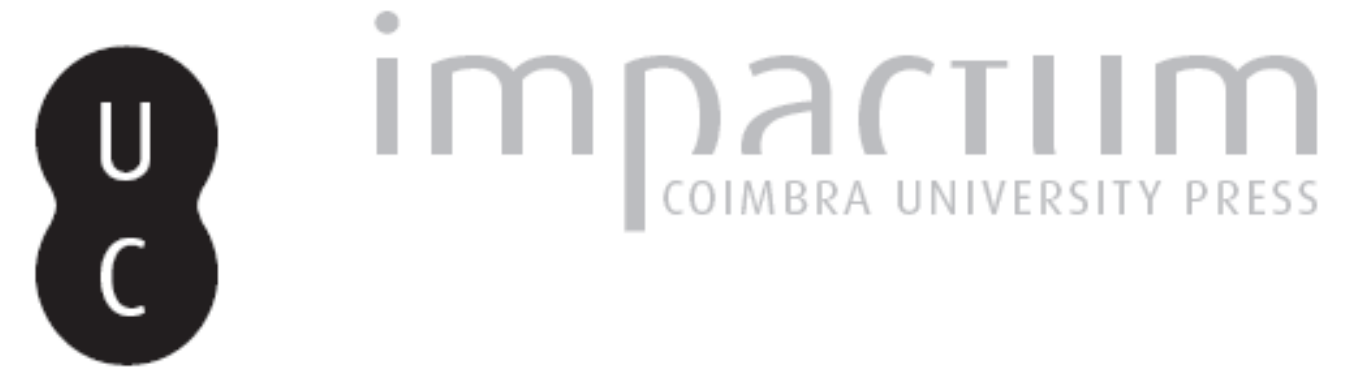

\title{
Pedagogia do projecto
}

Autor(es): $\quad$ Bandeirinha, José António

Publicado por: Editorial do Departamento de Arquitetura

URL persistente:

URI:http://hdl.handle.net/10316.2/37322

DOI:

DOI:http://dx.doi.org/10.14195/1647-8681_3_7

Accessed : $\quad$ 26-Apr-2023 15:04:50

A navegação consulta e descarregamento dos títulos inseridos nas Bibliotecas Digitais UC Digitalis, UC Pombalina e UC Impactum, pressupõem a aceitação plena e sem reservas dos Termos e Condições de Uso destas Bibliotecas Digitais, disponíveis em https://digitalis.uc.pt/pt-pt/termos.

Conforme exposto nos referidos Termos e Condições de Uso, o descarregamento de títulos de acesso restrito requer uma licença válida de autorização devendo o utilizador aceder ao(s) documento(s) a partir de um endereço de IP da instituição detentora da supramencionada licença.

Ao utilizador é apenas permitido o descarregamento para uso pessoal, pelo que o emprego do(s) título(s) descarregado(s) para outro fim, designadamente comercial, carece de autorização do respetivo autor ou editor da obra.

Na medida em que todas as obras da UC Digitalis se encontram protegidas pelo Código do Direito de Autor e Direitos Conexos e demais legislação aplicável, toda a cópia, parcial ou total, deste documento, nos casos em que é legalmente admitida, deverá conter ou fazer-se acompanhar por este aviso. 


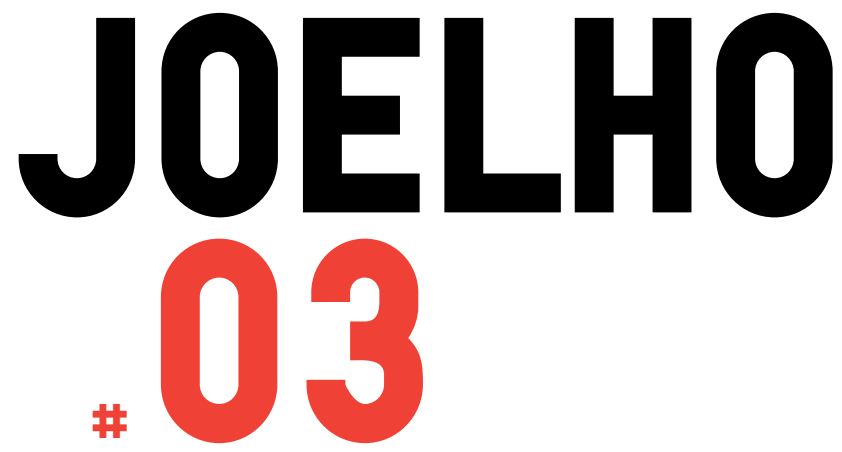

\section{VIAGEM-MEMÓRIAS: APRENDIZAGENS DE ARQUITECTURA}

Coordenação:

Alexandre Alves Costa

Domingos Tavares

Exposição Viagem

Exposição Memórias

Luis Mansilla

Alexandre Alves Costa

Domingos Tavares

SCA FoL DiNG
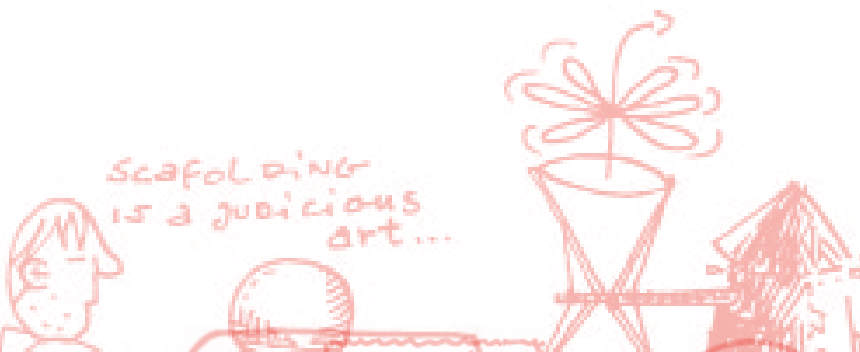

Jorge Figueira

José Miguel Rodrigues

José António Bandeirinha José Fernando Gonçalves

Paulo Providência

Gonçalo Canto Moniz Armando Rabaça

Patrícia Miguel

Bruno Gil

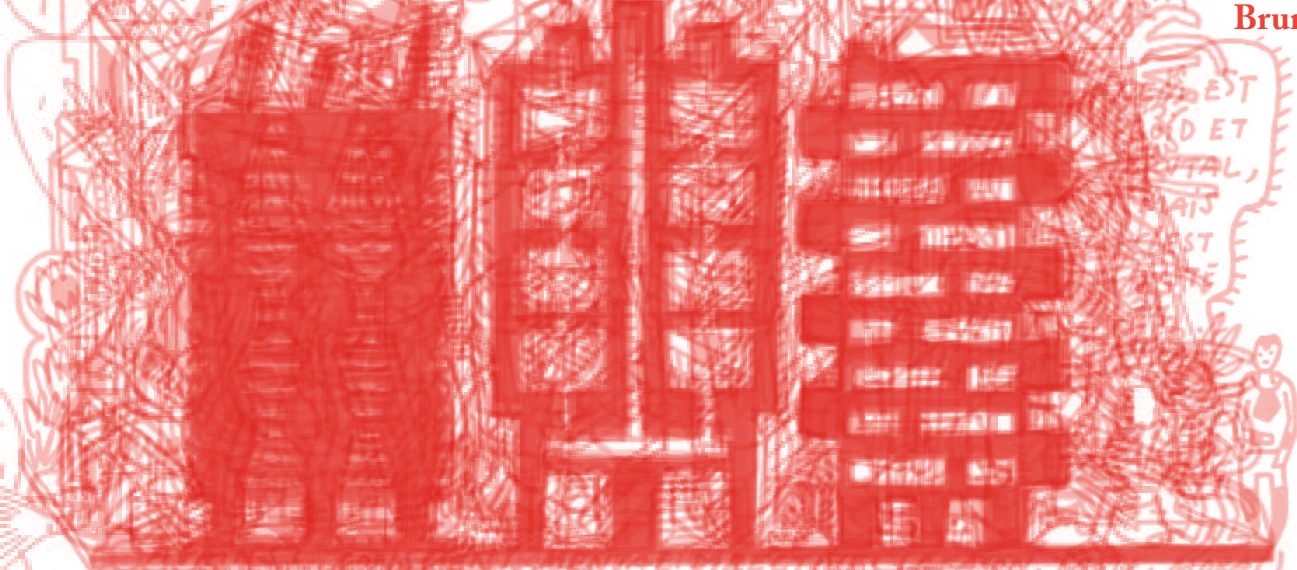

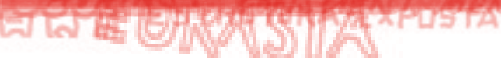


José António Bandeirinha Pedagogia do Projecto

"The architect as well as the teacher are practicing an art: an art of doing."

Jean-françois Mabardi, "Teaching Architecture - Texts and Tradition" AA. WV. Writings in Architectural Education, Copenhaga, EAAEIAEEA, p. 21 . 
Abertura, prudência, compreensão, permissividade por vezes, dúvida, vontade, intransigência

(Siza, 1993, 69)

\section{Quadro Científico-pedagógico das Disciplinas de Projecto}

O texto que ora vos apresento incide sobre um conjunto de disciplinas de frequência anual do Curso de Mestrado Integrado em Arquitectura do Departamento de Arquitectura da Universidade de Coimbra - as disciplinas de Projecto.

A disciplina de Projecto I funcionou pela primeira vez no ano lectivo de 1989-1990, ministrada sob a orientação do Professor Alexandre Alves Costa. Era, na altura, uma disciplina do $2^{\circ}$. Ano do Curso, uma vez que que a disciplina que introduzia a propedêutica laboratorial do Projecto no âmbito pedagógico do 10. Ano se intitulava então Introdução à Arquitectura. Esse primeiro ano constituiu, de certo modo, um momento fundador, que cunhou indelevelmente no devir desta escola uma perspectiva determinada da aprendizagem da Arquitectura.

A partir daí, porém, e desde o primeiro momento, foi preocupação das direcções do Curso convidar professores de Projecto que pudessem contribuir, com os seus saberes disciplinares e metodológicos para a geração de um carácter próprio. Sem querer menosprezar, de nenhuma forma, todos ou qualquer um dos chamados "professores de carreira" que, tal como eu, têm vindo a ministrar em continuidade as disciplinas de Projecto, gostaria aqui de enunciar, homenageando-os, os professores que, ao longo dos anos, foram sendo convidados, e ajudaram, com o seu magistério, a consolidar a nossa identidade.

Fernando Távora

Alexandre Alves Costa

Domingos Tavares

Raul Hestnes Ferreira

Gonçalo Byrne

Manuel Taínha
Manuel Graça Dias

Vítor Figueiredo

José Gigante

Paula Santos

Carlos Antunes

Diogo Seixas Lopes

\section{O papel das Disciplinas de Projecto no Plano Curricular} do Mestrado Integrado em Arquitectura

En la medida en que avanzan nuestros conocimientos relacionales $y$, por conseguiente, en la medida en que tanto las historias como las ciencias se entienden como relatos diversos en un verdadero pluralismo epistemológico, parece diluirse la idea de que la arquitectura necesite, para su propria identidad, paradigmas incuestionables que la garanticen de forma permanente

(Solà-Morales, 2003, p. 264)

Do ensino magistral ao suporte tratadístico, da taxonomia positivista à beauté oitocentista, do handwerk bauhausiano às reformas pedagógicas 
dos anos sessenta, os sistemas de formação em Arquitectura têm tido como suporte fundamental uma relativa constância do conteúdo semântico do termo Arquitecto (Cf. Mabardi, 2002). Com efeito, ao resultado final dessa formação corresponde um perfil profissional tautologicamente estabilizado por séculos de lentas e firmes adaptações metodológicas aos sucessivos contextos sociais, culturais, físicos e tecnológicos ${ }^{2}$ (Cf. Lefaivre; Tzonis, 2004, pp. 3-4).

Longe de se impor como risco de estagnação e de acomodação excessiva, essa estabilização tem, por um lado, contribuído para a criação de uma centralidade disciplinar que, quer sob o ponto de vista ontológico, quer sob o epistemológico, se tem vindo a assumir como plataforma de entendimento e de discussão com outras áreas do saber, enriquecendo e diversificando, de sobremaneira, o seu próprio corpus teórico. Por outro lado, tem permitido consignar a prática formativa, aquilo a que poderíamos também chamar a tradição de aprendizagem, como instrumento fundamental de consolidação da já referida centralidade. Como?

Em vez de considerar a prática do projecto na formação como um desígnio instrumental obsoleto, em desuso, a abater, desconfiando obsessivamente das suas potencialidades pedagógicas e, pior ainda, das suas "certificações" científicas, colocamo-la num patamar central de estabilidade que possa permitir a sua permanente evolução periférica, que potencie a progressiva adaptação às condições reais do exercício profissional.

Pelo que diz respeito à obtenção de determinados objectivos pedagógicos, a prática instrumental na formação em Arquitectura pode, em função da sua relação com a realidade física, social e material do mundo que a envolve, situar-se num de três patamares distintos:

- simulação directa, quando procura evidentes relações de aproximação ao real, quando pode chegar a parecer uma encomenda profissional;

- emulação crítica, quando, do confronto com o real são escolhidas as condições mais favoráveis aos objectivos do exercício;

- abstracção conceptual, quando as condições físicas, sociais e/ou materiais do contexto são inventadas ou alteradas em função daquilo que se pretende.

Assim, os diversos tipos de exercício a executar durante as aulas laboratoriais de Projecto aproximam-se mais de cada um destes patamares na medida em que pretendam oferecer aos alunos, como meta pedagógica, respectivamente, maior capacidade cognitiva no plano socio-profissional, mais especificidade instrumental no plano metodológico ou maior dinâmica relacional e conceptual, no plano cultural.

Obviamente que nem estes tipos, nem os objectivos que lhes andam associados são estanques ou estáticos. Antes assentam em formulações elásticas, quer sob o ponto de vista absoluto, quer nas relações que 
estabelecem entre si, podendo a todo o momento gerar tipos híbridos, que congregam componentes de dois ou mesmo dos três tipos.

A disciplina de Projecto I é, assim, a primeira de uma série de cinco disciplinas anuais que, neste âmbito pedagógico, constituem a estrutura central do curso. Essa responsabilidade é-lhe conferida pelo seu peso curricular, pela sua duração temporal mas, sobretudo, pelo seu carácter de objectivação material do ofício que os estudantes ambicionam como futuro. Cabe-lhe, por isso e para além do mais, um papel muito específico, um papel de "revolvimento" das predisposições metodológicas dos estudantes e do seu posterior "redireccionamento" no sentido do exercício projectual, suportado pela relação empírica com o espaço e com as potencialidades de transformação que lhe estão associadas, um papel que, enfim e por facilidade, poderíamos chamar iniciático.

O significado da disciplina de Projecto I está, por isso, intrinsecamente ligado a uma frente de captação de motivações individuais que vão desde a cultura arquitectónica à cultura artística no sentido mais lato e mais aberto, desde o interesse pela experimentação manual ao gosto pela sistematização tecnológica, desde a potenciação genérica da sensibilidade plástica ao aprofundamento específico desta ou daquela preferência cultural, deste ou daquele saber científico.

\section{A função do Arquitecto. Necessidades pedagógicas da formação do Arquitecto}

\section{The architect as well as the teacher are practicing an art: an art of doing}

(Mabardi, 2002, p. 21)

Referir a centralidade disciplinar da arquitectura pressupõe a existência, mesmo que só no plano abstracto, de um significado notativo forte, tão forte que possui a sua padronização socialmente instituída. Essa padronização, embora de contornos variáveis, não anda muito longe, pelo que diz respeito às funções associadas à profissão, da elaboração de esquemas, de sistematizações e de desenhos com objectivos muito precisos de transformação do espaço, em função de um determinado programa. Um padrão que estabelece um modo aberto e livre de pensar e de relacionar as coisas do Mundo, articulando-as entre si de acordo com um equilíbrio que pouco divergirá da tríplice base vitruviana.

Evoluir em torno do uso pedagógico das potencialidades dessa prática significa também considerá-la como uma das condicionantes essenciais da especificidade que caracteriza a formação em Arquitectura. Como se manifesta, então, essa especificidade?

Manifesta-se de muitos modos, mas não há dúvida que, em primeira análise, se pode perceber através de uma determinada ordem ${ }^{3}$ metodológica que caracteriza o exercício do projecto de Arquitectura. Essa ordem tem uma raiz unitária, que é a permanente inquietação acerca da disposição das coisas no espaço, a qual conduz directamente 
ao impulso transformador que caracteriza o estado de espírito dos arquitectos. Depois, porém, ramifica-se segundo uma estrutura dúplice, que corresponde também a duas atitudes diferenciadas, embora complementares e desejavelmente simultâneas.

Uma é a atitude da observação, mais analítica, mais voltada para uma interpretação atenta e aturada do real, atitude a partir da qual, como veremos mais adiante, o desenho de compreensão tem um papel preponderante.

Outra é a atitude de projecto, de intensa convivência com inputs de vária ordem, do programa à sociedade, dos modelos formais aos modelos conceptuais, da optimização funcional à optimização plástica, da racionalidade material à racionalidade económica, do saber tecnológico ao saber empírico e tantos, tantos outros.

Em qualquer destas atitudes, porém, e daí a sua raiz comum, predomina o recurso a um efeito de "coesão de conjunto" que irá monitorar todo o processo de projecto, de um modo, por vezes, radical. Trata-se de estruturar a geração, projecto a projecto, de um sistema que conduza a complexidade de articulação entre as diversas escalas ${ }^{4}$, de um mecanismo que facilite e, simultaneamente, garanta a unidade do processo e a coerência entre as suas diversas partes. Trata-se do famoso, embora inominável, elã do todo e das partes, das partes e do todo e das partes entre si, que vem sendo sucessiva e incessantemente evocado por inúmeros textos de Teoria da Arquitectura, diacronicamente perfilados ao longo da tradição epistemológica, "la dure obligation du tout" (Boudon, 1991, p. 187), um pressuposto que se insinua como se fosse uma pulsão metodológica, que é aceite quase como configuração default, que tem sido muito pouco analisado e que condiciona de sobremaneira os critérios de avaliação crítica da obra de Arquitectura.

Por um lado, é natural que assim suceda. O mais simples dos projectos de Arquitectura encerra em si uma enorme diversidade de dados, os quais, por sua vez, jogam com articulações de escalas diversas, com sobreposições temporais diferenciadas e não diacrónicas, com subjectividades de ordem ética e/ou social e, para além disso, ambicionam muitas vezes recorrer a experimentalismos tecnológicos e a saberes científicos. Torna-se, por isso, mais conveniente e, sobretudo, mais cómodo gerar sistemas que, caso a caso e projecto a projecto, articulem e hierarquizem esses dados, em vez de procurar um sistema universal que os valide sempre, independentemente das suas diferenças circunstanciais.

Por outro lado, essa pulsão metodológica que ambiciona o alcance do equilíbrio final entre as partes e o todo, leva a uma procura que, sob o ponto de vista do raciocínio, não se esgota no projecto, e daí a sua já referida condição de duplicidade. Está também presente na fase de análise, mesmo que esta seja, como é desejável, simultânea com a de projecto, porque essa pulsão gera, inclusivamente, a integração do processo de compreensão no processo de transformação, levando a que sejam uma e a mesma coisa. 
Com o tempo e com a maturação da aprendizagem dos

estudantes, começa a insinuar-se nas suas formas de ver o mundo, começa a instituir-se como um desejo mais ou menos obsessivo de ordenar as coisas no espaço segundo regras, metáforas, conceitos, modulações... Inevitavelmente, nos primeiros anos do curso, provoca também mudanças, tão habituados que estavam a outros sistemas de compreensão, mais decompostos, mais elementares e mais cumulativos.

Trata-se também, portanto, nestas disciplinas de Projecto, de preparar os alunos para o confronto gradual com essa pulsão. Por vezes, é necessário levá-los a saborear a imersão lenta nesses diferentes domínios de entendimento e de raciocínio, outras vezes, torna-se mais útil, sob o ponto de vista pedagógico, mergulhá-los abruptamente, esperando que a sua própria autonomia instrumental os conduza até um destino mais seguro.

Pelo que diz respeito à aprendizagem em Arquitectura, esta dupla coesão, que percorre a integridade física e conceptual da obra e se instala na integridade narrativa do próprio processo, está também, como é lógico, muito dependente da natureza idiossincrática de cada estudante, da sua história, da sua cultura, da sua origem...

Daí, a necessidade de um apoio mais individualizado, um apoio que, na medida do possível, tente potenciar individualmente, e ao longo dos diversos exercícios, a evolução dos alunos, dialogando com cada um deles, ajustando formulações metodológicas ao conhecimento do modo como se colocam perante os problemas de projecto. Obviamente que esta circunstância do apoio individual está, de sobremaneira, dependente da perspicácia do docente, do modo como entende o aluno e como faz reverter esse entendimento em motivação, em raciocínio e em evolução instrumental. É, contudo, um risco inevitável a correr.

\section{O papel do desenho}

\section{A poem is a poem, a building is a building, architecture is} architecture, music is... it's all structure. Essential. I use it as a language. Architects are organically responsible today to have their language run parallel with their structure. You know what I'm getting at? The new edge in architecture. I cannot do a building without building a new repertoire of characters of stories of language and it's all parallel. It's not just building per se. It's building worlds

(Hejduk, 1991, p. 61)

As disciplinas de Projecto têm, assim, de pôr em destaque, pelo menos na sua componente prática, um contrato pedagógico com os estudantes que passa, por um lado, pelo entendimento gradual das premissas metodológicas associadas ao exercício do projecto de Arquitectura, em particular, do tal sistema de "coesão de conjunto", já atrás referido, dada a sua "incompatibilidade" com as formulações tradicionais de ensino, às quais os estudantes vêem habituados. Por outro lado, 
passa pela capacitação instrumental para o exercício do projecto, passa pela compreensão do papel do desenho como motor dessa capacitação.

O desenho de projecto pode ter também diversas formulações. Quando, porém, se trata de tempos iniciais de aprendizagem, destacamos dois tipos elementares:

- o desenho de concepção, que permite a inscrição no papel de formas e previsões que estudam, resolvem e confirmam a solução arquitectónica;

- a modelação de maquete, que tem a mesma função, mas que permite complementar e verificar, sob o ponto de vista tridimensional, a solução arquitectónica.

Quanto à primeira, é o modo mais directo de veicular a ideia de transformação do espaço que é solicitada ao aluno de Arquitectura. Traduz em sinais de comunicação gráfica, amplamente reconhecíveis, as propostas de síntese que a encomenda suscita. Para além de estabelecer esta espécie de ligação privilegiada entre a ideia e a sua verificação, este tipo de desenho favorece e faz persistir essa tal "coesão" de que se falava atrás, pois permite congregar dados aparentemente desconexos, ou mesmo antagónicos. Cumpre ainda o papel de interligar o gesto corporal, as sucessivas formulações da inteligência e o signo de comunicação - "permite a conjugação de alternativas para a forma a buscar, o acerto sucessivo do corpo com o lugar, da sensibilidade com a inteligência, da funcionalidade com a liberdade plástica da criação pessoal." (Carneiro, 2002, p.16) É imprescindível como meio de fixação do pensamento, seja do impulso mais imediato, seja da ideia mais amadurecida. Permite gerar, através de suportes transparentes, uma narrativa em torno da evolução da solução, uma narrativa não linear, com evoluções e retrocessos, com verificação permanente do que já se conquistou e do que já se superou. $O$ uso de transparências no desenho de projecto permite tomar consciência, a cada momento, do estado do trabalho, do seu carácter evolutivo, das formas mais persistentes e das mais espúrias, confere-lhe, enfim, o estatuto de processo.

Mas o desenho tem igualmente um papel fundamental a desempenhar como meio de interpretação e de compreensão da realidade que circunda o objecto de concepção projectual. $\bigcirc$ desenho fixa na memória o contexto mais complexo, colhe-o de modo mais perene que qualquer outro modo de recolha, fotografia, filme ou vídeo. A atenção posta no acto de desenhar a envolvente, o uso do desenho para melhor entender o real, garante marcas indeléveis na memória, que se revelarão úteis ao longo de todo o processo. Para além do mais, este tipo de desenho de compreensão dificilmente almeja objectivos puramente analíticos, ao desenhar o contexto os alunos estão já a propor, ainda que de modo tacteante, a sua transformação, estão já a projectar. Quase intuitivamente, é o próprio acto de desenhar que os leva para 
os caminhos da formatação do impulso do projecto, e mesmo que, no início, alguns deles tenham dificuldade em gerir esta dúplice função do desenho de compreensão, são insistentemente incentivados a fazê-lo. As pequenas distorções de escala, o local de enquadramento do desenho, o realce deste ou daquele pormenor e o obscurecimento daqueloutro, todas as circunstâncias, mesmo as aparentemente inconscientes, contam como expressão de um desejo, que é já o desejo de transformação subjacente a todo o projecto de Arquitectura. O caderno, ou a prancheta, de campo são, portanto, suportes tão importantes quanto as transparências. É através deles que se aferem os primeiros contactos com o objecto físico do projecto, é neles que nascem os primeiros sinais, mesmo que ténues, do projecto a realizar.

Quanto à segunda das formulações do desenho de projecto, a modelação em maquete, tem a função de verificar, quase em simultâneo e a três dimensões, as propostas que o papel fixa como mais seguras. Falamos, obviamente, de maquetes muito rudimentares, que permitem constantes mudanças e adaptações, objectos em permanente transformação a que chamamos maquetes de trabalho. Cumprem, para além do mais, um papel fundamental na motivação e no desenvolvimento do trabalho dos alunos que, por diversas razões, têm mais dificuldade em se ajustar, sob o ponto de vista instrumental, à primeira das formulações.

Pelo que diz respeito à sua função metodológica, estas duas formulações do desenho não estão, entre si, vinculadas nem a uma ordem sistemática, nem a qualquer hierarquia posicional. Articulam-se e interagem de modo constante e ininterrupto. Constroem-se maquetes a partir dos desenhos e desenham-se as maquetes para aferir os desenhos, são testes usados para testar os testes, são pontes sucessivas a superar dúvidas e dificuldades pontuais, são lanternas que iluminam um caminho empírico que vai desde a nebulosa das hipóteses ao rigor das certezas. São, para além do mais, obra manufacturada, que pressupõe o uso gestual e instrumental do corpo de cada um dos alunos, corpo que é o padrão de mediação, por excelência e em exclusivo, do espaço que pretendemos transformar.

O desenho assistido por computador representa um outro prolongamento instrumental, mais avançado, da relação entre o corpo e o espaço que o desenho à mão propicia. Como todos os prolongamentos, é útil logo que estejam consolidadas as solicitações metodológicas acima referidas.

\section{Tempo de aprendizagem}

Atravesar la dualidad teoría-práctica, desplegar discursos transversales, construir plataformas desde las que poder ver el presente y el pasado, desde distintas y nuevas observaciones, es la tarea ineludible de este momento

(Solà-Morales, 2003, p. 266) 
Dos objectivos pedagógicos enunciados destaca-se um primeiro desenvolvimento da capacidade instrumental dos alunos para o exercício do projecto de Arquitectura. Mas o projecto aqui enunciado não é uma entidade em si mesma, não existe sem a corporização que lhe é dada, em primeira análise, pelas condições da encomenda - programa, contexto, valor - e, num segundo momento, pela concretização arquitectónica das soluções, cujo principal objectivo é, por estranho que pareça, extinguir esse mesmo projecto, transformando-o em obra. E é, precisamente, à luz desta condição etérea e parasitante do projecto que podem ser colocadas duas das mais relevantes questões que se lhe põem, na actualidade (Cf. Gregotti, 2000, 126-127):

Uma diz respeito ao facto de, cada vez mais, o projecto ser encarado como uma proposta asséptica, constituído em mera previsão de mercado para um futuro estático, do ponto de vista temporal, um futuro sem desfeitas nem contradições. Perdido o paradigma moderno do futuro, o projecto devia antes tender a assumir-se como pesquisa em torno das condições do presente, como resolução em Arquitectura do conjunto de tensões subjacentes às contradições do presente.

A outra diz respeito a uma característica própria da Arquitectura, enquanto prática, e, sobretudo, enquanto prática artística, que é a de trabalhar sobre condições empíricas e sobre as contradições e as mudanças dessas mesmas condições. Esse é o seu material, está no seu centro epistémico e é indestrutível. Esse material, bem como as contradições que lhe são inerentes, devem ser analisados e criticados, recorrendo aos meios e aos pontos de vista da própria Arquitectura.

A matéria prima do projecto contemporâneo, que já não deriva de futuros redentores, não deve deixar-se definhar sob a dependência de sondagens de mercado, por rigorosas que sejam. A matéria prima do projecto contemporâneo constrói-se a partir do conhecimento profundo das contradições do presente, contradições entre a longa duração da Arquitectura e da cidade e o imediatismo da economia de mercado, entre a efemeridade do desenho e a perenidade da obra, entre planeamento e desregulação, entre atributos plásticos e segurança normativa, entre preocupação ambiental e rendibilidade imediata, entre a manipulação responsável do espaço e o apelo do epidérmico, do cosmético, do in.

Por isso, as disciplinas de Projecto visam, no essencial, introduzir a temática do projecto, dar-lhe consistência metodológica e abrir-lhe todas as perspectivas teóricas que for possivel. Visam, através da descoberta do método, abrir campo a todas as asserções vindouras, estimulando os alunos a descobrirem-nas, seja através da emoção, seja através da razão, da ciência, da arte, da técnica, ou de todas em conjunto.

A questão do cruzamento entre a teoria e a prática é, porém, a questão essencial, pelo menos desde o momento em que começámos a olhar para o ensino da Arquitectura numa perspectiva universitária. O pretenso academismo que, em nome da "independência intelectual", condena a contaminação da teoria com o exercício continuado 
da Arquitectura tem-se revelado tão nefasto para a evolução cultural da disciplina quanto o mito da prática intuitiva, do virtuosismo acrítico e inculto.

Daí o acompanhamento permanente, nestas disciplinas, por acções e acontecimentos que veiculem a prática e, numa perspectiva aberta e multicultural, lhe confiram, gradualmente, dinâmicas de credibilidade e de sustentação teórica.

A prática em si mesma existe para consolidar a capacidade instrumental que viabiliza o método. Tem como condições o programa, o contexto e a crescente capacidade para usar a dimensão teórica como um, entre outros instrumentos.

Privilegiará, como já foi referido, o desenvolvimento das capacidades de entender o espaço e as suas transformações em detrimento das de resolver plasticamente as superfícies, por muito atraente que seja essa resolução. Privilegiará a compreensão estrutural das formas em detrimento da subjugação imediata à visualidade do mundo contemporâneo. Pelo que diz respeito ao convívio com as condições da cultura arquitectónica, privilegiará o entendimento do mundo global através da dimensão caracterial e local, e, especularmente, o entendimento do local através da compreensão esclarecida e crítica do global, privilegiará um entendimento transtemporal e hiperestésico, fortemente subvencionado pelo reconhecimento da universalidade da dimensão clássica, em detrimento da perseguição hameliniana da flauta do momento presente, "do que se está a fazer 'de novo' no mundo", do obsessivo up to date. Para usar uma metáfora, simples e injusta como todas as metáforas, privilegiará os livros em detrimento das imagens.

MODA: Sou a Moda, tua irmã.

MORTE: Minha irmã?

MODA: Sim. Não te lembras que nós duas nascemos da caducidade?

(Leopardi, 1996, p. 324)

\section{Conclusão}

Aquilo que me interessa, aquilo que ensino, é a necessidade da variedade do projecto; é a necessidade de unidade dentro do projecto.

Não há unidade sem variedade. É este o fundamento, a ideia-base, a filosofia do meu trabalho

(Távora apud Esposito, Leoni, 2005, p. 13)

Num primeiro impulso, confesso que procurei fugir à referência crua, directa.

Não porque achasse que a influência pedagógica do magistério de Fernando Távora pudesse colidir, fosse de que modo fosse, com a desejada aptidão para dirigir e realizar trabalho científico independente (Diário da República, 2007, alínea c do Arto. 30), que é suposto que um professor universitário tenha como atributo. Nada disso. 
Fi-lo por receio de não conseguir estar à altura da citação. Digo-o sem modéstia.

Mais tarde, contudo, apercebi-me da inutilidade da fuga. Todo o trabalho de programação, tal como o de concepção e o de criação, tem um ou vários modelos subjacentes.

Ao longo de muitos anos, no Porto e em Coimbra, as lições de Távora foram abrindo a aprendizagem da Arquitectura a muitas gerações de alunos recém-entrados no ensino superior. Muitos alunos e muito diferentes entre si. Uns, mais ansiosos, sem conseguir esconder a ambição e a vontade de atingir, rapidamente e com êxito, a aptidão profissional. Outros, mais hesitantes, em debate permanente com a imensidão de dúvidas que uma disciplina como esta, tão avessa a verdades absolutas e a asserções homogeneizadoras, pode gerar. Todos, sem excepção, encontraram nessas aulas um caminho para desbravar e/ou um conforto para as suas inquietações. Eu fui apenas um, entre tantos outros.

Mas, mais do que isso, essas aulas tinham ainda uma função congregadora. Quase como num toque a rebate, convocavam-nos para uma missão difícil, mas gratificante. Uma missão que apaziguava as tensões do confronto com a realidade e que dava sentido e intensidade à nossa relação cognitiva com essa mesma realidade, que transformava o conhecimento, racional e analítico, das coisas do mundo em impulso emocional para a sua transformação. Convocavam-nos para uma missão que não mais deixaria de interagir com as nossas próprias vidas: o exercício da Arquitectura.

Por essa circunstância, constituíam também, embora inconfessadamente, um ritual iniciático, mas ao contrário do habitual discurso iniciático dos mestres sobre a dificuldade e excelência do campo do conhecimento de que se julgam especialistas únicos, Távora explicou aos seus alunos que desenhar é tão natural como respirar e que o ofício de fazer arquitectura, como qualquer outro ofício, não é apanágio de alguns iluminados (Costa, 2007, p. 131).

Tão natural como respirar era o modo como Távora se referia ao método, mas tão natural como respirar era o modo como ensinava, confrontando frontalmente as tensões do mundo e da vida sem nunca virar a cara à complexidade. É ela que nos oferece, em constância, um leque de contradições a que não bastam os $180^{\circ}$, do qual nascem lições de Arquitectura (Siza, 1993, p. 69).

Hoje, sei que era assim porque, e para além do mais, a pedagogia de Fernando Távora não tem a ver com modelos, respostas sistemáticas, know how. Não exclui ferramenta. Mas tem a ver com a humana condição, abertura, prudência, compreensão, permissividade por vezes, dúvida, vontade, intransigência (Siza, 1993, p. 69).

Não sei distinguir com exactidão aquilo que, na minha actividade, está directamente relacionado com aquela influência pedagógica. Mas sei que procuro estimular os alunos para essa mesma missão, sei que lhes quero falar, com abertura, na humana condição. Procuro fazê-lo prudentemente, deixando campo aberto para a individualidade 
da emoção e para a generalidade da razão. Procuro respeitar a dúvida de cada um, com compreensão, permissividade por vezes, mas apelo sempre à virtude do conjunto, à intransigência do consenso, à clarividência da cidade. Procuro relacionar conhecimento com emoção. Sei que as respostas podem ser mais que as perguntas e, assim, procuro trabalhar com a diversidade. Se há algo de mais imperativo naquilo que tenho para lhes dizer é que não se vira a cara à complexidade - é ela a essência do real, é ela a matriz do nosso ambiente de trabalho. Desconfio de enquadramentos excessivamente sistemáticos, deliberadamente redutores, e fico angustiado com as respostas fechadas e definitivas. Modelos e ferramenta, por sua vez, têm de estar sempre ao lado da vontade, sempre à mão, para o que der e vier...

Não posso, por tudo isso, deixar de dedicar este artigo à memória do magistério de Fernando Távora. Assumo o risco de a contaminar com todas as imperfeições que as palavras que escrevi possam eventualmente ter, e que só a mim se devem, mas não posso, em consciência, deixar de o fazer.

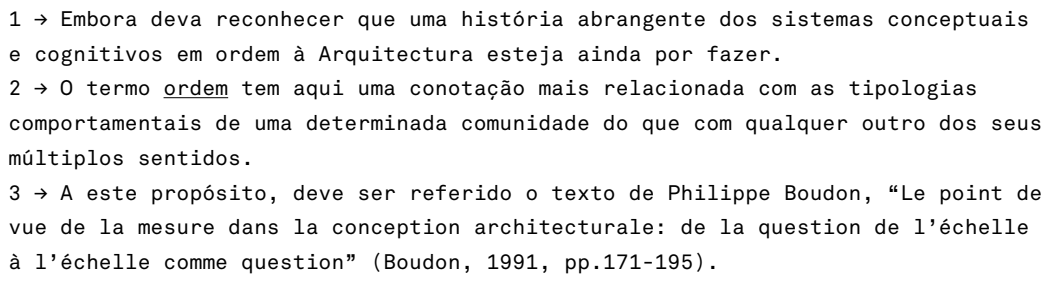

\section{Bibliografia}

Carneiro, A. (2002). Conceituando ao redor deste desenho. In AA. VV.. Desenho Projecto de Desenho. Drawing Design Project. Instituto de Arte Contemporânea.

Costa, A. A. (2007). Fernando Távora. In Introdução ao Estudo da História da Arquitectura Portuguesa. Porto: FAUP Publicações.

Diário da República (2007). 1ª Série, $\mathrm{n}^{\circ}$. 116: Decreto-Lei $n^{\circ} .239 / 2007$ de 19 de Junho, alínea c) do $\operatorname{Art}^{\circ} .3^{\circ}$.

Gregotti, V. (2000). Diciassette lettere sull'architettura. Bari: Laterza, 2000.
Hejduk, J. (1991). The Architect Who Drew Angels. In Shapiro, D. [interview by], Architecture and Urbanism, 244.

-

Lefaivre, L., Tzonis, A. (2004). The Emergence of Modern Architecture. A Documentary History from 1000 to1810. Londres e Nova lorque: Routledge.

Leopardi, G. (1996). Diálogo da Moda e a Morte. in Leopardi, G. (1996). Poesia e Prosa. Rio de Janeiro: Nova Aguilar.

-

Mabardi, J.-F. (2002). Teaching Architecture - Texts and Tradition. In AA.VV. Writings in Architectural Education. Copenhaga: EAAE/AEEA.
Philippe Boudon, P. (dir.) (1991). De l'architecture à l'épistemologie. La question de l'échelle. Paris PUF. -

Siza, Á. (1993). A Propósito da Arquitectura de Fernando Távora. In Trigueiros, L. (ed.), Fernando Távora. Lisboa: Editorial Blau.

-

Solà-Morales, I. (2003). Inscripciones.

Barcelona: Gustavo Gili.

Távora, F. apud Esposito, A., Leoni, G. (2005). Fernando Távora. Opera completa. Milão: Electa. 